\title{
Indicators of Good Governance for Administrators of the Primary Educational Service Area Office
}

\author{
Akchatree Suksen ${ }^{1}$, Wirot Sanrattana ${ }^{1} \&$ Paisan Suwannoi ${ }^{1}$ \\ ${ }^{1}$ Program in Educational Administration, Mahamakut Buddhist University, Isan Campus, Thailand \\ Correspondence: Wirot Sanrattana, Doctor of Education, Program in Educational Administration, Mahamakut \\ Buddhist University, Isan Campus, Thailand.
}

Received: November 8, 2019

doi:10.5539/ies.v13n4p84
Accepted: January 6, $2020 \quad$ Online Published: March 9, 2020

URL: https://doi.org/10.5539/ies.v13n4p84

\begin{abstract}
This research aimed at accomplishing the following: (1) to build theoretical model, then to test its fitness with the empirical data; and (2) to investigate the factor loading of the main factors and sub-factors, as well as those indicators, which were compared to the determined criteria. The research applied descriptive research methodology to collect the data using a 5-scale questionnaire. The population consisted of 1,100 administrators in the Primary Educational Service Area Office (PEASO). The determination of the sample group size was established by applying the rule of population sample parameter proportion of 20:1, which was equal to 820 participants. From the 795 questionnaires, which were returned, the results of the data analysis were concluded by analyzing confirmatory factors using the AMOS program. It was determined that the theoretical model and empirical data were relevant given the following criteria: a Relative Chi-Square $>3.00$ and a Root Mean Square Error of Approximation > 0.0. In addition, the Goodness-of-Fit Index, Adjusted Goodness of Fit Index, Comparative Fit Index, and Normed Fit Index were found to be between $0.90-1.00$. Moreover, the factor loading of the main factors was from $0.86-1.06$, which is higher than the determined criteria $(0.70)$, while the factor loading of the sub-factors and the indicators ranged from $0.73-0.95$ and $0.30-1.00$, respectively. These numbers were also higher than the determined criteria of 0.30 , indicating that as a result of the research, the theoretical model could be used as a guideline to improve better governance for the administrators of PEASO with construct and content validity.
\end{abstract}

Keywords: indicators, good governance, administrators of the primary educational area service office (PEASO)

\section{Introduction}

\subsection{Introduce the Problem}

The concept of Good Governance includes government, administration, and management, as well as how to control businesses. Moreover, Good Management can be used within both the state and private sectors. It is a well-known principle that can be applied in today's work administration because it helps to empower and encourage organizations to reach their potential and to become more effective. This results in the growth of the organization, reliability of third parties towards the organization, and continuous development. Because the Office of the Civil Service Commission, Thailand (2010) has proposed good governance principles in the form of regulations to the Office of the Prime Minister and because Royal Decrees were established with respect to the principles of good administration in 1999, six principles have been recognized. These are Morality, the Rule of Law, Accountability, Participation, Responsibility, and Cost-effectiveness (Economy). These principles have been established to support the well-being of the people and to assist in the achievement of the government's tasks, making them effective and worthy. Therefore, the following should be undertaken: 1) no unnecessary work procedures should be carried out, 2) the government's tasks focusing on making improvements should be up-to-date, and 3) facilities for the people, as well as their demands, should be met and regularly assessed.

Based on Thailand's current situation, it can be seen that the county is developing at the international level and as well in ASEAN. Therefore, in accordance with the National Strategy Protocol 2018-2037 (Office of the National Economic and Social Development Council, Thailand, 2018a) and the 12th National Economic and Social Development Plan 2017-2021 (Office of the National Economic and Social Development Council, Thailand, 2018b), which are targeted at developing the country, it is essential for the country to build organizations that operate with good governance and transparency. Investigations, carried out by other organizations, can serve as a 
guarantee that Thailand is progressing in every aspect within the international community. Hence, in their administration, the PEASO administrators must apply the principles of Good Governance. For this, the aim of the researcher was to create a theoretical model, which manifests the structural relationship between the main factors, sub-factors, and the indicators of the good governance, which can be used as a guideline for the development of the PEASO administrators.

\subsection{Importance of the Problem}

After the review of 18 various sources of related literature, which consisted of Boonmee (1998), Prime Minister's Office, Thailand (1999), Ministry of the Interior, Thailand (2000), Office of the Civil Service Commission, Thailand (2005), Sittikumchorn (2008), Thongsut (2008), Buason (2008), Limsakunsirirat (2008), Sopchokchai (2010), Samudavanich (2011), Chanpakdee (2012), Aimatnoi (2012), Mahakhun (2013), Department of Corrections, Thailand (2015), King Prajadhipok's Institute, Thailand (2018), United Nations Development Program (UNDP) (1997), Organization for Economic Co-operation and Development (OECD) (2004), and The United Nations Economic and Social Commission for Asia and the Pacific (UNESCAP) (2009), it was discovered that there are 16 factors in the theoretical factor framework of Good Governance. However, having considered the relevant factors from their high frequency (16 and higher) during this research, it was found that there are four models, which can be considered in the proposal of the main factors as a measurement model of Good Governance: Transparency, the Rule of Law, Participation, and Accountability.

The results of such synthesis served as the starting point in the continuous search for answers to this question: "What are the important sub-factors for each main factor?" The result of the synthesis showed that each main factor had consisted of four models and their sub-factors as the measurement model: (1) the measurement model of Transparency with four important sub-factors: (a) disclosure, (b) management control, (c) structure and function, and (d) monitoring and evaluation; (2) the measurement model of Rule of Law with four important sub-factors: (a) independence, (b) legal governance, (c) justice, and (d) equality; (3) the measurement model of Participation with four important sub-factors: (a) participation in planning, (b) participation in decisions, (c) participation in the practice, and (d) participation in monitoring and in carrying out evaluations; and (4) the measurement model of Accountability with four important sub-factors: (a) performance responsibility, (b) self-responsibility, (c) prestige, and (d) realization of duty.

When combining the model of the measurement of Good Governance with the model of the measurement of the four main factors, the result was the model of the structural relationship of the indicators of Good Governance with the four main factors and 16 sub-factors as shown in Figure 1 below. 


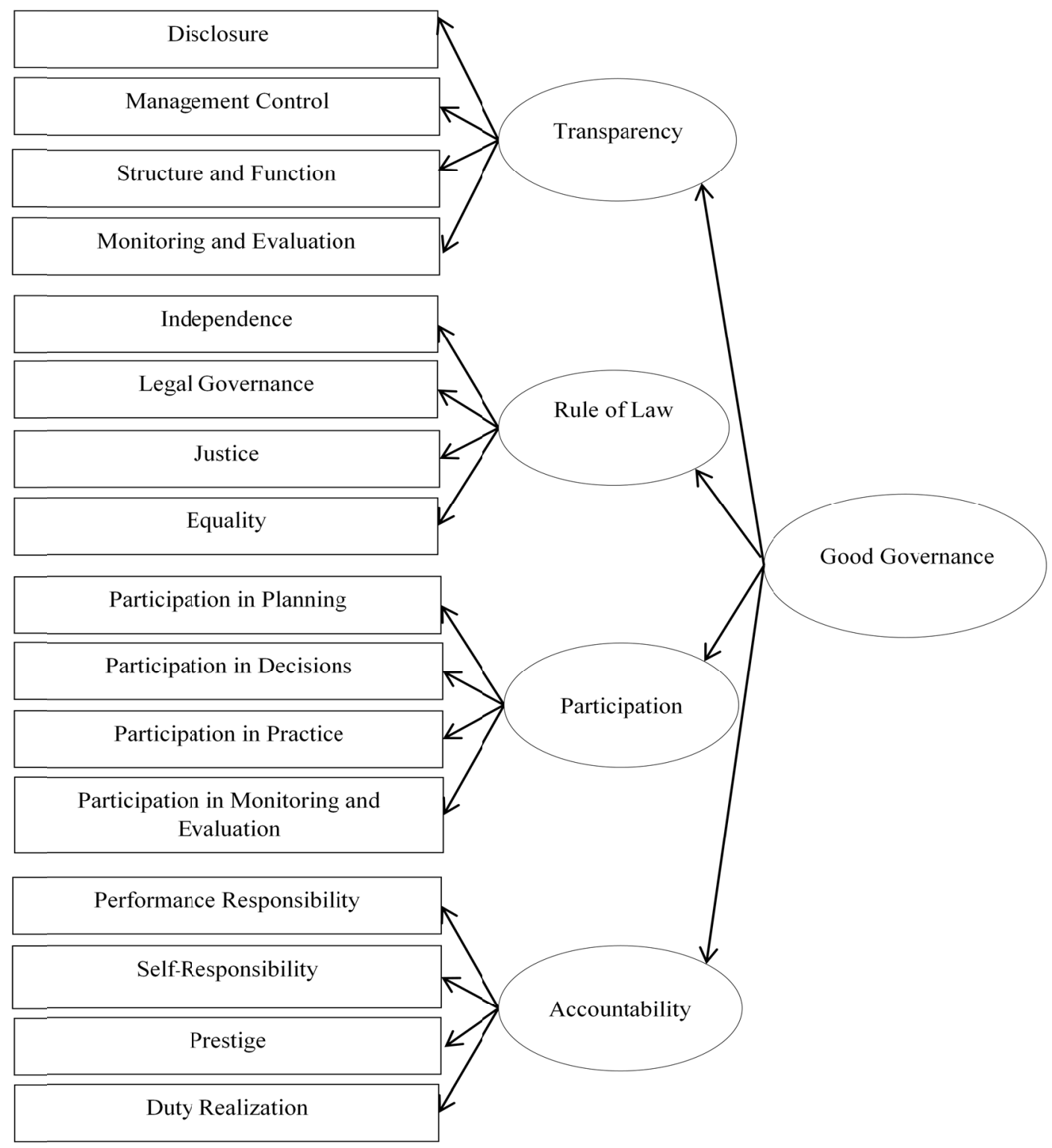

Figure 1. The model of structural relationship of the indicators of good governance

From this model, the researcher was able to examine the operational definition of each of the sub-factors in order to connect the indicator determinations and to acquire 60 reflective indicators of the behaviors of Good Governance for each sub-factor. This is considered to be a complete model of the structural relationship of the indicators of Good Governance in three levels, which are the main factors, sub-factors, and indicators. Moreover, it is the theoretical or hypothetical model for the research that the researcher had previously developed from theories and research. The researcher tested the model's relevance with the empirical data collected from a sample group of administrators at the Primary Educational Area Service Office under the Office of the Basic Education Commission of the Ministry of Education around the country.

\subsection{Research Objective}

This research aimed at testing the developed theoretical model with empirical data. If the fitness was found to be in accordance with the determined criteria, then the model could be used as a prototype to develop Good Governance for the PEASO administrators under the Office of the Basic Education Commission of Ministry of Education. The reason for this is that they were chosen to be used as the target group in this research in order to prove whether or not the model would be structurally reliable. Furthermore, it was possible to prioritize the development by considering the factor loading of the main factor, sub-factors, and indicator levels because in the research, there 
was also an investigation of the factor loading of the main factors, sub-factors, and the indicators.

\subsection{Research Hypothesis}

The model of structural relationship of the indicators of Good Governance, which was used in this research, was created and developed by reviewing literature from various sources with the following purposes in mind: (1) synthesizing the main factors, sub-factors, and the indicators and (2) utilizing the Max-Min-Con Approach in Kerlinger \& Lee's Research Methodology (2000) to determine: (a) the sample group size, (b) sampling, (c) the creation and development of an effective research tool, (d) data collection, and (e) the application of suitable statistics. Thus, the researcher set the research hypothesis to predict the answers as follows:

1) 60 research indicators are suitable for the model of structural relationship of the indicators of Good Governance by considering the attitude criteria from Kornkarn (2003): the average value should be 3.00 or higher with a coefficient of dispersion at $20 \%$ or lower.

2) The structural relationship model of the indicators of Good Governance, was developed from theories and literature. It was found to be relevant to the empirical data and is considered to be in accordance with the following: (1) Hair, Black, Babin \& Anderson (2010)'s attitude criteria - relative Chi-square: CMIN/DF) range from $1-3$ or lower; (2) a Root Mean Square Error of Approximation (RMSEA) of lower than 0.05 ; (3) a Goodness-of-Fit Index (GFI) with a range from 0.90 - 1.00; (4) an Adjusted Goodness-of-Fit Index (AGFI) with a range from $0.90-1.00$; (5) a Comparative Fit Index (CFI) with a range from $0.90-1.00$, and (6) a Normed Fit Index (NFI) with a range from $0.90-1.00$.

3) The factor loading for the main factor should be 0.70 or higher (Farrell \& Rudd, 2009), and for the sub-factors and the indicators, it should be 0.30 or higher (Tacq, 1997).

Moreover, if the theoretical model corresponds to the research hypothesis, it can't only be used as a guideline in the research with respect to the development of the target group in terms of structure, content, and priority. It must, however, also be able to be applied in academic and practical activities. For example, it can achieve the following: (1) assist in gaining new knowledge, which is suitable within the context of Thai society and can be employed in further research or undergo further development in the future; (2) be used for research in other fields, such as in structural equation modeling, research and development, or in participatory action research; (3) help to reduce data by putting the data in a form, which can be easily used in order to reduce the repetition of the data (It represents theoretical data management, and with proof from the research, the data become useful for organizations to apply, follow, review, and make decisions about their work at all levels.); (4) be used by the administrators of the Primary Educational Area Service Office as a guideline in planning for or in creating an assessment for Good Governance so that the strengths and weaknesses in staff development can be examined, as well the corresponding problems; (5) be useful when monitoring tasks when needing to make decisions and to evaluate the work achievements of individuals; and (6) be utilized as a guideline to control the organization via a process of establishing pertinent regulations with respect to: (a) the standards of work performance or the standards of achievement for the organization; (b) a process by which an individual, a group of individuals, or an organization codify the rules for an individual, a group of individuals, or an organization to follow; (c) the aims that the organization sets to ensure its success; and (d) the organizational goals, which are used to ensure that the members of the organization operate in ways that will fulfill the standards and goals and which will place greater emphasis on the desired behaviors.

\section{Research Methodology}

\subsection{Identify Subsections}

There are three methods to develop the education indicator, namely (1) pragmatic definition is the method the researcher selects the variables by himself/herself in order to present the model (2) theoretical definition is method the researcher constructs the model by applying the relevant theories and research and employ the model in reality or asking the experts to scrutinize the model before use (3) empirical definition is the method the researcher construct the model by applying the relevant theories and research and the model will be examined with the empirical data. If there is the concordance between the theoretical model and the empirical data collected from the random samples and the data is analyzed by confirmative factor analysis, the data can be utilized for the future research (Wiratchai, 2002). In this research, the empirical definition is used to develop the indicators as Sanrattana (2018) points out that it is likely to be more scientific because the empirical data is used to collect the random samples from the population. Consequently, there is no weakness in term of the bias from the researchers' or the experts' personal sensation and experience as below.

\subsection{Population and Sample}

This research is a descriptive research in which the population for the research was composed of 1,100 
administrators in the Primary Educational Area Service Office under the Office of the Basic Education Commission of the Ministry of Education (Office of the Basic Education Commission, Thailand, 2017). In order to determine the size of the sample group, Gold (1980)'s Rule of Population Sample Parameter Proportion 20:1 was applied. The number of the parameters was from five latent variables, 16 observed variables, and 20 influence lines, making 41 parameters and equaling 820 subjects in the research sample group.

\subsection{Instrument}

The research tool, a questionnaire, consisted of two parts: 1) the informants' status which was on the listing form and 2) questions relating to behaviors of the Good Governance among the PEASO administrators, which was in a 5 -scale rating form which is the highest, most, medium, less, and the least. The content was categorized in accordance to the main factors, sub-factors, and the indicators. There were 60 questions. This questionnaire was checked for the index of item-objective congruence (developed by Rovinelli and Hambleton in 1977 cited in Turner \& Carlson (2009) is a procedure used in test development for evaluating content validity at the item development stage) by 3 educational administration experts and 3 evaluation experts. Then, the questionnaire was tried out with 30 samples which is not the samples used in the research. Data were analyzed to find the alpha coefficient of reliability by employing Cronbach's method. The results revealed that the questionnaires contain the alpha coefficient of reliability equal 0.97 . It is important to note that the figure was higher than the determined criteria (0.70) (Prasertratasin, 2003).

\subsection{Data Collection}

To collect the data from the sample group of 820 subjects, Multi-Stage Random Sampling was used, and afterwards, the questionnaires were distributed to the administrators via post. The subjects were asked to return the questionnaires within a time period of 6-weeks. Of those 820 questionnaires sent, 795 questionnaires were returned (97\%).

\subsection{Data Analysis}

To analyze the data, a computer program was used to calculate the statistical values as follows: (1) the frequencies and percentages to show primary data of the sample group; (2) the average and coefficient of dispersion to test the suitability of the indicators; (3) Pearson's correlation coefficient and Barlett's statistic to consider the suitability of the variables, which was later analyzed for confirmatory factors and Kaiser-Meyer-Olkin (KMO)Test for Sampling Adequate to consider the sufficiency of the questionnaire for the Confirmatory Factor Analysis; and (4) the first order of Confirmatory Factor Analysis and second order of Confirmatory Factor Analysis to test the relevance of the theoretical model with the empirical data using AMOS.

\section{Results}

The results of the analysis for the averages and coefficients of the dispersion values to test the suitability of the indicators to be selected and placed in the model showed that 60 indicators had scored average values ranging between $4.23-4.74$ and that the coefficient of dispersion had ranged between $11.35-15.86$. Thus, they were all determined to be sufficiently suitable to be put into the model because the values were 3.00 or higher and the coefficient of dispersion was $20 \%$ or lower.

When testing the relevance of the four measure models, which had been developed from theories and the related literature, the results of the first order of Confirmatory Factor Analysis showed that they were relevant to the empirical data by considering the statistical values of each of the models as follows: (1) the measurement model of transparency had CMIN/DF $=1.17, \mathrm{RMSEA}=0.01, \mathrm{GFI}=0.99, \mathrm{AGFI}=0.97, \mathrm{CFI}=1.00$, and NFI $=0.99$; (2) the measurement model of Rule of Law had CMIN/DF $=1.06, \mathrm{RMSEA}=0.00, \mathrm{GFI}=0.99, \mathrm{AGFI}=0.97, \mathrm{CFI}=1.00$, and NFI $=0.99$; (3) the measurement model of Participation had CMIN/DF $=1.53$, RMSEA $=0.02, \mathrm{GFI}=0.99$, $\mathrm{AGFI}=0.97, \mathrm{CFI}=0.99$, and NFI $=0.99$; and (4) the measurement model of Accountability had CMIN/DF $=0.93$, $\mathrm{RMSEA}=0.00, \mathrm{GFI}=0.99, \mathrm{AGFI}=0.98, \mathrm{CFI}=1.00$, and NFI $=0.99$. Additionally, the results of the second order of Confirmatory Factor Analysis of measurement model of Good Governance showed that the model had $\mathrm{CMIN} / \mathrm{DF}=1.60, \mathrm{RMSEA}=0.02, \mathrm{GFI}=0.99, \mathrm{AGFI}=0.96, \mathrm{CFI}=1.00$, and NFI $=1.00$. These statistical values were in accordance to the determined criteria mentioned in the research hypothesis: (1) a Relative Chi-square: (CMIN/DF) from $1-3$ or lower, (2) a Root Mean Square Error of Approximation (RMSEA) of lower than 0.05, (3) a Goodness-of-Fit Index (GFI) from 0.90 - 1.00, (4) an Adjusted Goodness-of-Fit Index (AGFI) from 0.90 1.00, (5) a Comparative Fit Index (CFI) from $0.90-1.00$, and (6) a Normed Fit Index (NFI) from $0.90-1.00$. The results of the data analysis are as shown in Table 1. 
Table 1. The Results of the First and Second Orders of Confirmatory Factor Analysis

\begin{tabular}{|c|c|c|c|c|}
\hline \multirow{2}{*}{ Factors } & \multicolumn{3}{|c|}{ Factor Loading Matrix } & \multirow{2}{*}{$\begin{array}{l}\text { Coefficient of Prediction } \\
\qquad\left(\mathrm{R}^{2}\right) \\
\end{array}$} \\
\hline & $\lambda$ & S.E. & $\mathrm{t}$ & \\
\hline \multicolumn{5}{|c|}{ The results of the first order of Confirmatory Factor Analysis } \\
\hline \multicolumn{5}{|c|}{ Measurement Model of Transparency } \\
\hline Disclosure & 1.02 & - & - & 1.04 \\
\hline Management Control & 0.79 & 0.02 & $29.66 * *$ & 0.62 \\
\hline Structure and Function & 0.83 & 0.02 & $37.59 * *$ & 0.69 \\
\hline Monitoring and Evaluation & 0.89 & 0.02 & $42.60 * *$ & 0.80 \\
\hline \multicolumn{5}{|c|}{$\mathrm{CMIN} / \mathrm{DF}=1.17, \mathrm{RMSEA}=0.01, \mathrm{GFI}=0.99, \mathrm{AGFI}=0.97, \mathrm{CFI}=1.00$ and $\mathrm{NFI}=0.99$} \\
\hline \multicolumn{5}{|c|}{ Measurement Model of Rule of Law } \\
\hline Independence & 0.95 & - & - & 0.91 \\
\hline Legal Governance & 0.94 & 0.01 & $51.10 * *$ & 0.88 \\
\hline Justice & 0.89 & 0.02 & $43.24 * *$ & 0.79 \\
\hline Equality & 0.73 & 0.02 & $29.07 * *$ & 0.54 \\
\hline \multicolumn{5}{|c|}{$\mathrm{CMIN} / \mathrm{DF}=1.06, \mathrm{RMSEA}=0.00, \mathrm{GFI}=0.99, \mathrm{AGFI}=0.97, \mathrm{CFI}=1.00$ and $\mathrm{NFI}=0.99$} \\
\hline \multicolumn{5}{|c|}{ Measurement Model of Participation } \\
\hline Participation in Planning & 0.84 & - & - & 0.71 \\
\hline Participation in Decisions & 0.83 & 0.02 & $36.85 * *$ & 0.68 \\
\hline Participation in Practice & 0.89 & 0.02 & $35.68 * *$ & 0.79 \\
\hline Participation in Monitoring and Evaluation & 0.73 & 0.02 & $31.94 * *$ & 0.53 \\
\hline \multicolumn{5}{|c|}{$\mathrm{CMIN} / \mathrm{DF}=1.53, \mathrm{RMSEA}=0.02, \mathrm{GFI}=0.99, \mathrm{AGFI}=0.97, \mathrm{CFI}=0.99$ and $\mathrm{NFI}=0.99$} \\
\hline \multicolumn{5}{|l|}{ Measurement Model of Accountability } \\
\hline Performance Responsibility & 0.81 & 0.02 & - & 0.66 \\
\hline Self-Responsibility & 0.95 & 0.02 & $45.10 * *$ & 0.91 \\
\hline Prestige & 0.87 & 0.02 & $38.49 * *$ & 0.76 \\
\hline Duty Realization & 0.96 & 0.02 & $49.00 * *$ & 0.93 \\
\hline \multicolumn{5}{|c|}{$\mathrm{CMIN} / \mathrm{DF}=0.93, \mathrm{RMSEA}=0.00, \mathrm{GFI}=0.99, \mathrm{AGFI}=0.98, \mathrm{CFI}=1.00$ and $\mathrm{NFI}=0.99$} \\
\hline \multicolumn{5}{|c|}{ The results of the second order of Confirmatory Factor Analysis } \\
\hline Transparency & 0.86 & - & - & 0.74 \\
\hline Rule of Law & 1.04 & .02 & $42.08 * *$ & 1.08 \\
\hline Participation & 1.06 & .02 & $31.74 * *$ & 1.11 \\
\hline Accountability & 0.92 & .02 & $25.17 * *$ & 0.85 \\
\hline
\end{tabular}

The results of the factor loading test of the main factors, sub-factors, and the indicators showed the following: (1) the factor loading of the four main factors of Good Governance was positive (between 0.86 - 1.06) with every number being statistically significant at the level of 0.01 ; (2) the factor loading of the four sub-factors of Transparency were positive (between 0.79 - 1.02) with every number being statistically significant at the level of 0.01 ; (3) the factor loading of the four sub-factors of the Rule of Law were positive (between 0.73 - 0.95 ) with every number being statistically significant at the level of 0.01 ; (4) the factor loading of the four sub-factors of Participation were positive (between 0.73 - 0.89) with every number being statistically significant at the level of 0.01 ; and (5) the factor loading of the four sub-factors of Accountability were positive (between $0.81-0.96$ ) with every number being statistically significant at the level of 0.01 .

Moreover, the factor loading of the 60 indicators was also positive (between $0.30-1.00$ ) with every number being statistically significant at the level of 0.01 . This showed that the structural relationship model of the indicators of Good Governance for the PEASO administrators, which was comprised of four main factors, 16 sub-factors, and 60 indicators, had demonstrated positive factor loading as had been set in the criteria in the research hypothesis, which indicated that the factor loading of the main factors had been 0.70 or higher and 0.30 or higher for the sub-factors and the indicators.

\section{Discussion and Suggestions}

From the research results, it was found that the 60 indicators had shown an average value and coefficient of dispersion, which was set in the criteria. Therefore, it was found to be suitable and was able to be selected and 
placed into the model of structural relationship. The researcher believed that this had stemmed from the creation and development of the model used in this research, which employed the method known as Empirical Definition in which the model is determined with the proof of theories and research. A study by Wiratchai (2002) inspired the researcher to systematically and logically examine theories and research from various sources. Moreover, through a process of synthesizing, the researcher could conclude by correctly determining the main factors, sub-factors, and indicators, which were in accordance with the theories and research. This corresponds to a suggestion by Jongsathitau \& Pinmanee (1986 cited in Sanrattana, 2018), which states, "Quality test of the indicators in theoretical framework is essential - if the development of the indicators starts from poor quality theoretical framework, the result from the development will be poor as well no matter how good the statistical method is." This also corresponds to a suggestion by Sanrattana (2018): "The study of theories and research to determine the main factors, sub-factors, and indicators have to concern construct and content validity." In addition, the research needs to be concerned with the quality of the research methodology in accordance with Max-Min-Con Approach by Kerlinger \& Lee (2000), which states that when determining the size of the sample group, sampling is important, as well as creating and developing the research tool to be properly used in the research.

The results of the research found that the theoretical model is relevant to the empirical data by considering the statistical values set in the criteria and in the research hypothesis. It showed that the four main factors, 16 sub-factors, and 60 indicators had been expressed in the structural relationship model of the Good Governance. The results of this research can be useful for academic purposes, as well as for other applications with constructs and content validity. This also showed the validity of the theories and research, which had been derived from 18 different sources as previously mentioned. Therefore, those sources, examined by the researcher for this research, can be used as references. Additionally, it is relevant to the research and theories of Mandelbaum (2016), Minsky (2017), and University of Guelph (2018), all of whom have mentioned the factors used in this research as well. Therefore, this represents a technological advancement, which is quickly being developed and made readily accessible. Given the universal nature of the theories and research, they have been widely published around the globe. In this Era of Globalization, the use of technology makes transmitting data and information convenient, allowing us to gain access at anytime from anywhere. Technologicalization seems to have narrowed the world. According to Croucher (2004), globalization is a process in which the world's population is melted as one society. This process occurs because of the influence of economic, technological, social-cultural, and political collaborations. Furthermore, it is the result of technological development, which changed in the 21 st century (Technology Effect Changes in 21st Century), making technology become a key variable in the societal changes, traditions, morality, education, economy, and politics by using the Internet to communicate to each other globally (Gleeson, 2018).

The results of this research showed that the factor loading of the main factors, sub-factors, and the indicators were different, but were as set in the criteria of the research hypothesis. The researcher believes that the reason for this was due to the literature review conducted at the beginning of the study up until the time the hypothetical model was created with constructs and content validity for the research. This study also was investigated by the experts to determine the relevance between the main factors, sub-factors, and the indicators until the index of item-objective congruence was acquired (Turner \& Carlson, 2009) and was determined to be higher than the set criteria. It was also included in the creation of the questionnaire. The relevance of the questions was aligned with the indicators until the index of item-objective congruence was acquired and was determined to be higher than the set criteria. The result was the acquisition of accurate and valid data, which was able to be collected from the sample group. According to Sanrattana (2018), "The quality test of the indicators under the theoretical framework is intensely based on the theories and research in order to develop the structural relationship model, and the indicators must be from the theories and research which concern about the construct and content validity." Therefore, the results of this research study have shown that the model used in the study can be useful in field of academics and also has practical application with respect to both construct and content validity. In addition, it can be used to prioritize the main factors and the sub-factors, as well as the indicators for further development.

Putting the model into action. As mentioned at the beginning that if the developed theoretical model satisfies the research hypothesis, aside from being used as a guideline for the development of target groups used in the research with construct validity and content validity, it can also be used for academic and practical purposes in other cases, such as 1) helping to obtain new knowledge that is appropriate to the Thai social context, 2) can be used for other types of research possible, 3) helping to reduce data in a format that is easy to use, 4) use as a guideline in planning or creating evaluation criteria to determine the strength and weaknesses in the development of personnel in accordance with the problems, 5) use as a benefit for monitoring and evaluation, and 6) to be used as a guideline for organization control. The application of the model which consisting of 4 major components, 16 sub-elements 
and 60 indicators for the benefit of management and in order to have a conceptual framework that clear and easy to use, the researcher would like to present as a specific management conceptual framework at the major and minor components as shown in Figure 2 (ranking the importance according to the factor loading values from high - low for both major and minor factors).

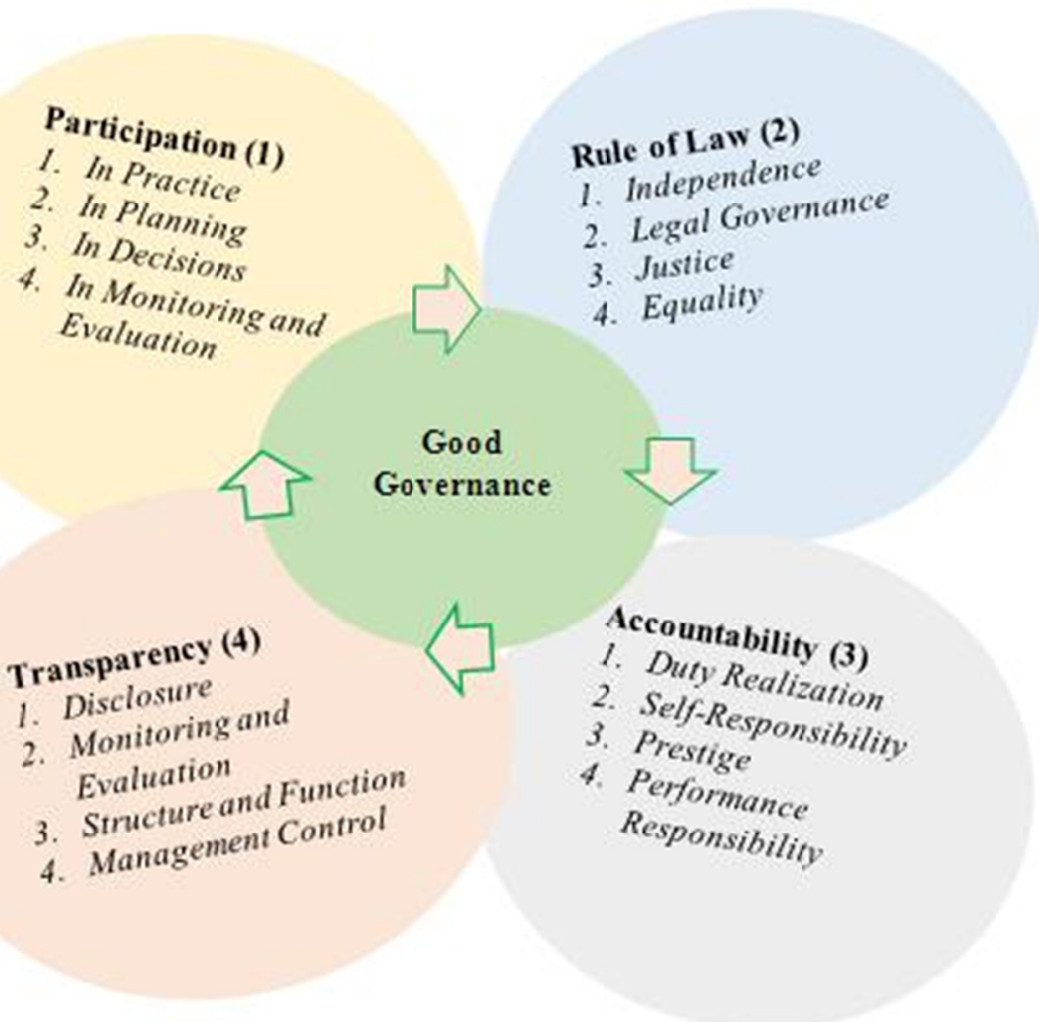

Figure 2. Oriented management framework for introducing the application of good governance model used

\section{References}

Aimatnoi, A. (2012). A study of the opinions of educational personnel towards the administration in accordance with the good governance principles of the administrators of the school administrators under the Office of Mae Hong Son Educational Service Area, Zone 1. Retrieved from https://bit.ly/2BwaNva

Boonmee, T. (1998). Good governance of national strategy in Thailand. Bangkok: Sai Than Publishing

Buason, R. (2008). Good governance of public universities: Plenty of case studies. Retrieved from http://www.rattanabb.com/html/reder0252.pdf

Chanpakdee, S. (2012). The use of good governance in academic administration of primary school administrators in Bang Kho Laem District, Bangkok Educational Service Area Office, Area 2. Retrieved from https://bit.ly/2MywHUU

Croucher, S. L. (2004). Globalization and belonging: The Politics of identity in a changing world. New York: Rowman \& Littlefield.

Department of Corrections, Thailand. (2015). Good government and social administration of the Department of Corrections. Retrieved from https://bit.ly/2W1ev9f

Farrell, A. M., \& Rudd, J. M. (2009). Factor analysis and discriminant validity: A Brief review of some practical issues. In D. Tojib (Ed.), ANZMAC 2009 Conference proceedings.

Gleeson, P. (2018). How is technology impacting the changes in the 21st century workplace? Retrieved from https://bit.ly/2MJDIie

Gold, R. Z. (1980). Introduction to bivariate and multivariate analysis. Glenview, Illinois: Scott, Foreman and 
Company.

Hair, J. E., Black, W. C., Babin, B. J., \& Anderson, R. E. (2010). Multivariate data analysis: A global perspective (7th ed.). New Jersey: Pearson Education Inc.

Jongsathitau, J., \& Pinmanee, S. (1986). Educational Index. Bangkok: The Veterans Organization of the Public House.

Kerlinger, F. N., \& Lee, H. B. (2000). Foundations of behavioral research (4th ed.). United States: Wadsworth, Thomson Learning.

King Prajadhipok's Institute, Thailand. (2018). Public participation. Retrieved from https://bit.ly/2KUgVo7

Kornkarn, S. (2003). Quality assurance development for government's educational institutes. A Thesis for the Doctor of Philosophy Degree in Educational Evaluation and Assessment of Srinakarinwirot University.

Limsakunsirirat, C. (2008). The Use of good governance in the administration of school administrators under the Chonburi Educational Service Area Office 1. A Thesis for the Master of Education Degree in Educational Administration, Rajabhat Ratchanakarin University Chachoengsao.

Mahakhun, V. (2013). Ethics, good governance and law. Bangkok: Child Psychiatric Forensics Development Foundation Youth and family

Mandelbaum, C. (2016). What is good governance? Retrieved from https://bit.ly/2HeFAwF

Ministry of the Interior, Thailand. (2000). Principles of good corporate governance. Retrieved from https://bit.ly/32vDwMw

Minsky, S. (2017). What is good governance, and why do we care? Retrieved from https://bit.ly/2psmtwr

Office of the Basic Education Commission, Thailand. (2017). OBEC information 2018. Retrieved from http://eva.obec.go.th

Office of the Civil Service Commission, Thailand. (2005). Good governance. Bangkok: Idea Square.

Office of the Civil Service Commission, Thailand. (2010). Guidelines for creating transparency standards for government agencies. Bangkok: Publisher, Office of the Civil Service Commission.

Office of the National Economic and Social Development Council, Thailand. (2018a). National strategy 2018-2037. Retrieved from https://bit.ly/2o7JN1Y

Office of the National Economic and Social Development Council, Thailand. (2018b). National economic and social development plan 12th (2017-2021). Retrieved from https://bit.ly/207JN1Y

Organization for Economic Co-operation and Development (OECD). (2004). Principles of corporate governance. Retrieved from http://www.oecd.org

Prasertratasin, S. (2003). Research methodology in social science. Bangkok: Puengfa Printing.

Prime Minister's Office, Thailand. (1999). Regulations of the Prime Minister's Office on the establishment of good governance in social affairs 1999. Bangkok: Office of the Civil Service Commission.

Samudavanich, C. (2011). Good Governance and educational reform, political reform. Bangkok: Sai Than Publishing.

Sanrattana, W. (2018). Research in educational administration: Concepts, guidelines, and case studies (4th ed.). Bangkok: Tipwisut.

Sittikumchorn, S. (2008). The use of good governance in private higher education institutions. Retrieved from https://bit.ly/2MXTBDV

Sopchokchai, O. (2010). Guidelines for applying good governance principles for local administration in order to propose models and guidelines for building good governance at the sub-district and village levels. A Thesis for the Master of Arts Degree. Graduate school, Maha Sarakham University.

Tacq, J. (1997). Multivariate analysis techniques in social science research: From problem to analysis. London: SAGE Publications Ltd.

Thongsut, V. (2008). Good management. Bangkok: Inthaphasa Publisher.

Turner, R. C., \& Carlson, L. (2009). Indexes of item-objective congruence for multidimensional items. Retrieved from https://bit.ly/2J2tsD1

United Nations Development Program (UNDP). (1997). Governance for sustainable human development, A 
UNDP policy document. Retrieved from https://bit.ly/2MwgzTQ

United Nations Economic and Social Commission for Asia and the Pacific (UNESCAP). (2009). What is good governance. Retrieved from https://bit.ly/2IV48jd

University of Guelph. (2018). Principles of good governance at the University of Guelph. Retrieved from https://bit.ly/2prm2Cs

Wiratchai, N. (2002). Indicators development of quality assurance and regional education management. Bangkok: Tarnaksorn.

\section{Copyrights}

Copyright for this article is retained by the author(s), with first publication rights granted to the journal.

This is an open-access article distributed under the terms and conditions of the Creative Commons Attribution license (http://creativecommons.org/licenses/by/4.0/). 